\title{
Urban filaments: from passageways of leisure-oriented space to emergent urban form
}

\author{
A. Furman \\ School of Interior Design, Faculty of Communication and Design, \\ Ryerson University, Canada
}

\begin{abstract}
In the contemporary urban condition there exist pedestrian systems that are not defined as sidewalks or streets - these are the urban filaments that weave themselves into the existing flow structures in historic and more recent urban forms. This paper will trace the challenges facing pedestrian spaces/urban filaments in the modernist experiment with urban form from a European and North American urban context - particularly in the urban cores of the city. Historically urban filaments emerged alongside historical and social changes, spurred on by the growing congestion of major traffic corridors, and responding to the opportunity to provide ameliorative social/cultural space between the existing patterning of public/private space. Innovation in technology and science propelled the form and helped to develop the language of urban filaments along until the automobile challenged the logic of the historic fabric; a largely pedestrian outlook of travel within the built fabric was replaced with a competing vision of the street. This is a tactical position for the city, it needs to continuously absorb and even rediscover various coping mechanisms to counteract the squeeze on pedestrian streetscapes. As a result, there are various qualities and kinds of public/private spaces that are arguably urban filaments, some emerging with other types enduring since before the Renaissance.
\end{abstract}

Keywords: pedestrianism, walking, modernity, pathways, public realm.

\section{Nolli's wisdom}

Giovanni-Battista Nolli's enduring genius to urban planners and designers, lies in his ability to understand how people in his time related to their surroundings. The Nolli maps (figure 1) as they are often referred, have stimulated interest in 


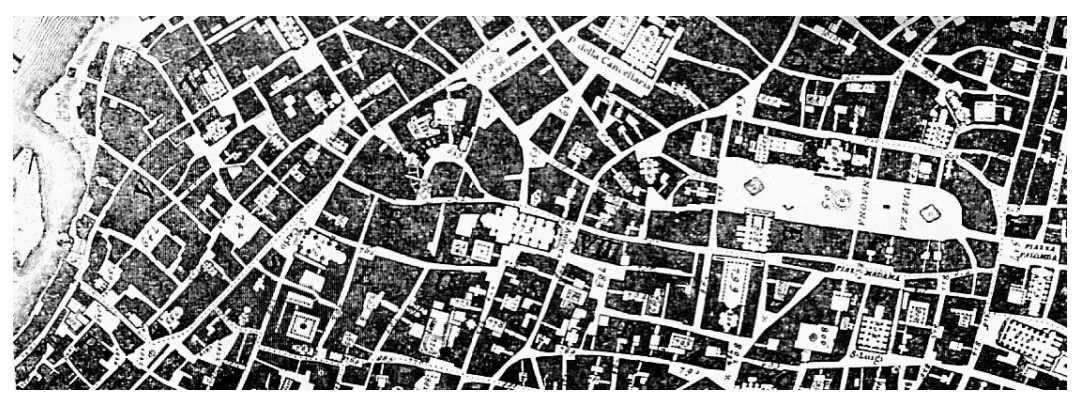

Figure 1: $\quad$ A fragment of Nolli's map of Rococo Rome, 1748.

public/private space, and they captivate us because of their power to help us to imagine a different way of using the same-layered streets and semiinterconnected circulation spaces today. With much being contested in contemporary cities between pedestrian movement and the private realm, it is useful to reflect on these relationships.

Matthijs de Boer's describes a flow of urban space that has many neutral qualities - the Rococo public realm. He writes: 'Church buildings also met many needs that had little to do with the spiritual (as can be seen in seventeenth century paintings). People walked their dogs in them; conducted business...churches functioned as more or less public, covered meeting places. Thus when... Nolli drew his famous map of Rome, he decided that church interiors should be left white, just like the streets and squares. Churches of that time shared a number of important characteristics with outdoor public space: they were always open, so in principle it was possible to walk in or out...it was relatively unimportant who the owner was; they used the building freely. There was a degree of maintenance, but no permanent resident; the visitor therefore infringed on no one's privacy. You could enter without being involved (my italics) in what the building was originally intended for.' [4, pp. 17-19]

This paper will build on ideas developed by the historians Fredrich Geist in his comprehensive Arcades: The History of a Building Type (The MIT Press, 1985) and Walter Benjamin in the Arcades Project. What is extracted and explored in both their work is the idea of a new pedestrian way, or type of movement system that is desired within a larger, pre-existing network of circulation in the city, from the late Victorian era, up until the present time.

There has been much that has already been said about the various meanings attributed to the use of the arcades in Walter Benjamin's writing, and what is of interest here is his particular view towards the uncanny nature of the arcade, and how it fits into the urban pattern. Figure 2 shows the original atmosphere of the space, successfully dense with people and signs; Benjamin writes: 'iron construction and technical design, one of the most important is the predominance of the vide over the plein, the empty over the full.' [3, p. 551]

The arcades are vastly important to modern urban design because they were a direct response to society's growing need for more space, in order to see and be seen, all the while taking in the cornucopia of new things available. They with 


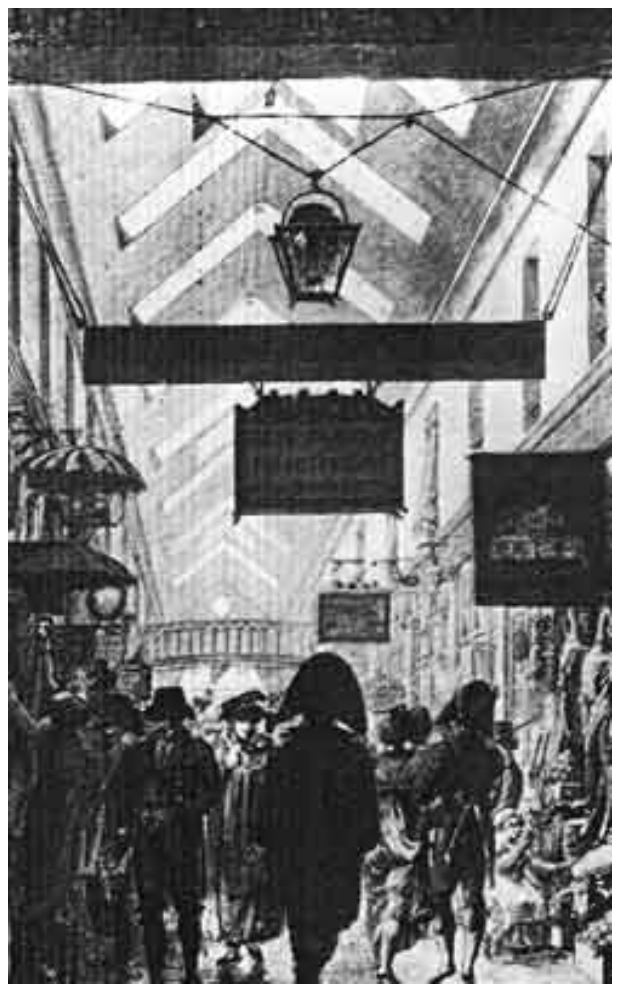

Figure 2: The Passage des Panoramas, ca. 1810, watercolour. The first arcade, showing the use of shop signage indoors, p. 36 from Benjamin [3].

their elegant stepping off point from the busier streets that justify them, they set into a dizzying motion in the latter half of the Victorian era, particularly in London and Paris - the exploration of large-scale public exhibition space along with the rationalized iron-frame building relating to pedestrian circulation and leisure space. Beyond the scope of this paper is the lost history of these connective spaces in other cities, particularly before large-scale demolition removed many fine examples from our collective records, needs to be written.

To begin, take the Crystal Palace, an example of a blown-up arcade, was constructed in London in 1851. It represents an attitude of internalized public temporary space that revels in the imaginative use of steel and glass, its revolutionary quality was, 'a framework of cast-iron girders accurately bolted together' [6, p. 252]. It and the many later exhibitions in Europe up until the turn of the century defined the era in the spectacle of the large-scale undertaking. The historian Sigfried Giedion summarizes these temporary giants, where 'construction becomes the form giver' (p. 275). These spaces anticipate the contemporary airports, lifestyle centres and office tower clusters. 


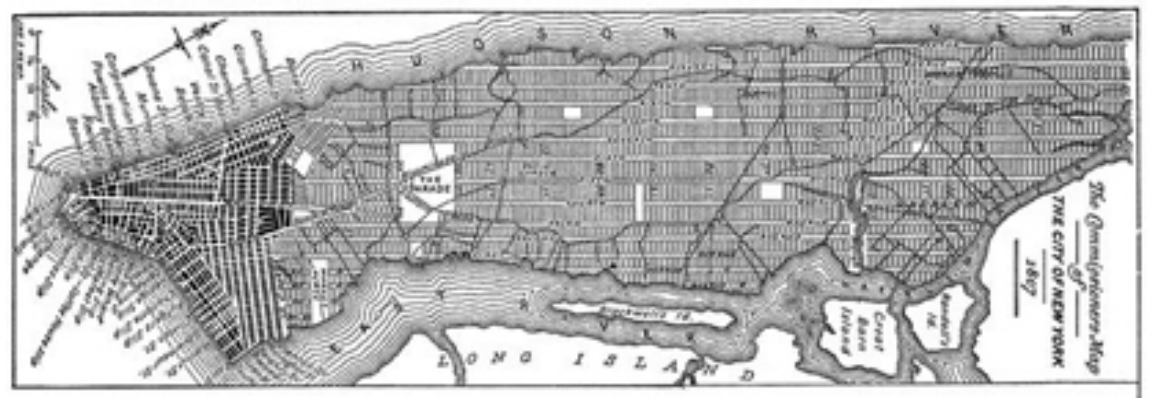

Figure 3: The subdivision of Manhattan streets into a gridded unit.

These developments of a rapidly growing availability of consumer products are contrasted with the Chicago school of urban construction, and New York's emerging attitudes to public space both public and private in relation to the largeblock building footprint, fig. 3 .

Phillipp Meuser, summarizes the character of European pre-modern town spaces in 'Experiments with Convention' as the separation of 'private space and public space that has as a rule developed from the division of land and property,' [8]. Urban filaments operate differently than this basic coding of public and private space. There is a blurring of both types of space; often it is a 'quasi' public or private condition. Recall that the earliest ideas of property had latent in it the idea of crossing over of one space in order to get to one's own property, such as early English right of way crossings through private lands.

\section{Circulation, gridiron, and short-cuts}

To understand the 'short cut' we need to begin with circulation. Adrian Forty explains how the term circulation emerged in France in 1628, and quickly became entirely part of the language of architecture [5, p. 87-8, 93]. Circulation is a powerful metaphor for urban filaments, and public space in general. It is very useful for us to use when describing interior and exterior publicly used spaces. Circulation as metaphor, anticipates the desire for construction that dematerializes the wall between street and shop; event space and interior...

Dankmar Adler and Louis Sullivan, the talented engineer-architect duo, are the creators of many significant structures. They stitched together the admired Auditorium building, an early mixed-use typology in Chicago in the last decade of the 1800's. They represented the North American embrace of iron and glass but with an important distinction- program was liberated from its prior chains of being an object building into a (continuous) street-fabric building. As mentioned by Geidion, they innovated everywhere, their 'interior iron structure (that) was very daring.' [6, p. 372]. Sullivan, in completing the Auditorium, was revisiting in plan, and shown here, in section, fig. 4, the complexity of the iron armature to create a void in the middle of the iron cage - this innovation of space meant that it was possible to have the union between the European attitude to cities as shown in plan in Nolli's maps, with the North American example shown in 
fig. 4, the surprising and enormous sectional transformation of the building to accommodate the theatre. It was a structure and attitude to the urban grid that was much ahead of its time, and if it became the model for zoning, instead of the New York setback rules for large structures of 1916 we might have had a very different relationship between the street and the buildings that line it the pervasive financial and residential tower zones.

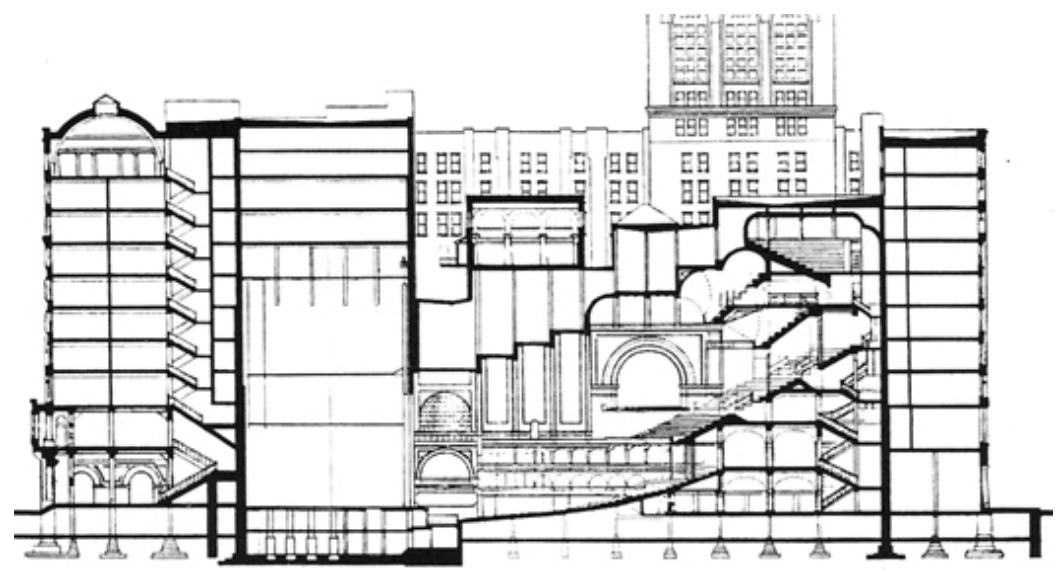

Figure 4: $\quad$ Auditorium building, longitudinal section, 1887-89.

Once the iron structures capabilities were known, the Chicago School began a new era that eclipsed the new spaces of the slim arcades and subsumed them into the collective memory of architecture-to be released one day when necessary, after the days of dense buildings are reexamined and found wanting.

Giedion writes of the attempts to solve the growing congestion between the shrinking realm of the pedestrian/and the growth of the automobile traffic problem through 'the use of the platform (my italics), an artificially constructed ground, runs through all the work of the successive waves of planners and designers after Sullivan's generation. It can be found everywhere where efforts are made to rescue the pedestrian from a chaotic intermingling with automobiles and trucks...' [6, p. 676, 680].

At some point in the project of modernity the desire or will to accurately represent the existing ground conditions of urban form using traditional methods of graphic representation (consider Nolli's plan drawings and other conventions) ceased to be a key concern in academia and practice. Site, or rather the transitory parameters of the surrounding urban conditions in which a project was situated in was selectively edited out to best suit the presentation of the scheme, in most cases relating to the form, and other formal aesthetic concerns. The public's ability to accept a new spatial event/space, rested on its ability to be shoehorned into a given context. This unique urban situation dealing with fit, especially the public dimension of circulation and patterns of use, has been conceptualized in modernist teaching and writing in most interesting ways, and has, unfortunately become abandoned as a concept for years, for many designers and civic decision- 
makers. Adrian Forty, in Words and Buildings, brings to the surface the mistranslation of the term context in modern circles, by implication- schools of architecture and design, as well as practitioners [5, pp. 133-135].

Forty traces back and finds that it was the architect Aldo Rossi's use of the term 'context' that was too crudely translated into English. In the original Italian it was lepreesistenze ambientali, or ambienti- the careful response of the surrounding pre-existences; in 'a dialogue with the surroundings, both in the immediate physical sense, but also as a historical continuum.' [5, p. 132] Forty connects the architectural community's use of the translated term - 'context,' and not ambienti, as the source of the misuse. What happens is a growing abstraction and relinquishing of the issues dealing with site/fit/pedestrian movement-off-the-site and more focus on formal concerns especially theory/aesthetics.

Colin Rowe, teaching in Cornell University, beginning in 1963 was using terms like context, to develop a deeper respect for site and context for modernist practice. He was interested in the relationships between objects and the spaces they occupied' specifically how program could be retained along formal relationships indoors, all the while being 'compressed and deformed to fit (the) irregular site without losing the distinctive features of the type.' [10, p. 135]. His studios helped to bring back some of Nolli's spirit of place in drawings and models. Below in figure 5 is an example of some of the work of his class.

European examples, by dint of their age, with many pre-Renaissance cities, show this spatial deformation of an idealized (largely symmetrically disposed) program as more of a given, so circulation (walking) routes that criss-cross in non-parallel ways are given more time in design and representations. What becomes apparent when comparing the logic of context/human scale is the question - where does this study of site and context reside in the gridiron of many North American examples of urbanity? How did it happen that it got lost?

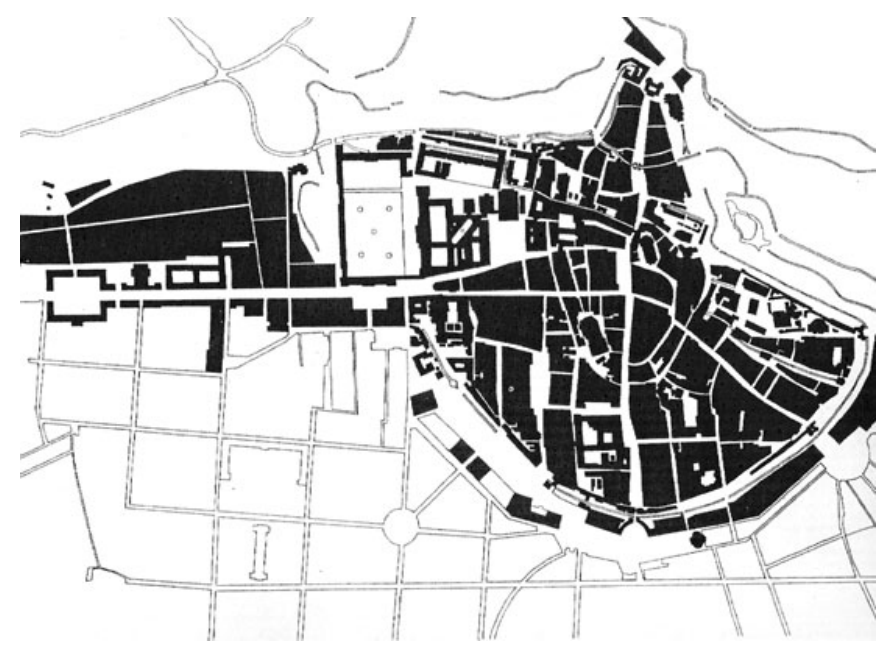

Figure 5: Student thesis figure/ground drawing, Wayne Copper, Munich. 
'In the dominant, received strain of the Beaux-Arts tradition, buildings were designed to retain their idealized compositional form even after being ascribed a specific site.' Redfield [9, p. 188].

How does it get resolved at the scale of the city, say for example New York's 800 foot-long blocks, and the human-scale of going about day-to-day activities where active responses to others occurs at street level? One firm voice in the 1960 's spoke into the void, and was heard; Jane Jacobs' writings have succinctly asked for the European scale of pedestrian movement overlaid on top of the gridiron model. Architectural theorists and practitioners heard, but for the most part tended to ignore the truth in the examples and focus on that much-discussed phase over a few decades of rejuvenation. In figure 6 Jacobs uses a diagram to show how short cuts make sense to build community, offer different routes for walking, and improve business along the connected paths.

Jane Jacobs writes of the purposes of block sizes and what happens to the large block in The Death and Life of Great American Cities. Using the argument that it would be 'inconvenient and pointless' to walk further ( 800 foot long block stretches of space) than needed to get to a point desired. She goes on 'if these long east-west blocks had an extra street cut across them---not a sterile "promenade" of the kind in which super-block projects abound, but a street containing buildings where things could start up and grow at spots economically viable: places for buying, eating, seeing things, getting a drink.' (p:180) and that long or large blocks 'sort people into paths that meet too infrequently, so that different uses very near each other geographically are, in practical effect, literally blocked off from one another.' Jacobs is challenging the lack of porosity of these blocks, she goes on to say 'thwart the potential advantages that cities offer to incubation, experimentation, and many small or special enterprises, insofar as these depend upon drawing their customers or clients from among much larger cross-sections of passing public...(they) also thwart the principle that if city mixtures of use are to be more than a fiction on maps, they must result in different people, bent on different purposes, appearing at different times but using the same streets.' Jacobs [7, p. 183]

Interestingly, she makes a point about not showing images in her landmark book but for this topic finds it useful to show a diagram (figure 6) 4 images explaining the short-cut patterns, in fact (pp.179-182). This suggests the dominance of pathway and shortcut logic in planning diagrams for infill and new development proposals, both for European and North American urban conditions, of which this paper will limit itself to for space reasons.

There really isn't any good reason why one wouldn't explore the options of opening up the Manhattan grid to pedestrian movement; it really becomes a series of different operations in scale; street-level interactions, podium slab relationships to a 7-storey edge, and then the tower, with or without setbacks. All scales could begin to layer one on top of another to provide view and natural lighting opportunity when constructing filaments in the dense block units. This opens up a European-influenced patterning of circulation ideas at the base of silent slabs- these are the spaces that need to be challenged first, as the other tactic of infill is well established for architecture and the related arts. 


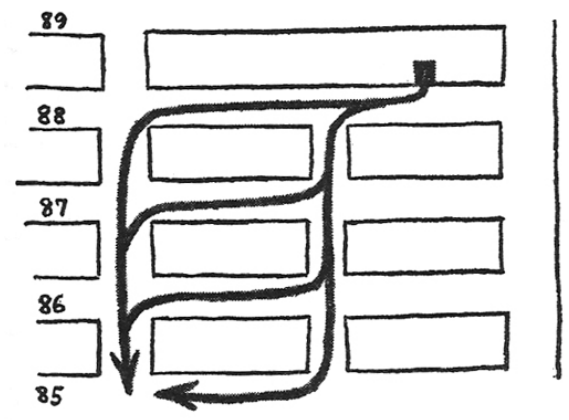

Figure 6: Jacobs' short-cut possibilities cut through the Manhattan grid.

\section{A working model for urban filaments}

Emerging from the shadows of the drafted presentations are the urban filaments, never really having disappeared, but now they need some basic classification; for the scope of this paper 3 basic types are suggested:

- the interior event space- it flows from the street and back into the street. It is ambiguous if it is an interior or exterior space, it may be seasonally sealed out to the elements, street-level shops, art galleries, courtyards, it can be a trolley;

- public interiors- this is unquestionably an 'interior' condition, the elements are more controlled than in the event space, a roof defines the interior even more than the walls do, it may use an intermediary circulation form to bridge with the street, historic arcades, hotel lobbies, airports, and modern urban mall (meaning that it has at least one party-wall condition) represent this type;

- and ribbons- the most unpredictable forms of the three, overhead and underground conduits with program, likened to wisps of smoke, pedestrian bridges, abandoned elevated rail lines, and staircases, esp. steep grade changes (stair $\neq$ street?)

As urban needs evolve, the private and publicly owned city spaces are becoming more aware of this need to provide comfort, and ones need to have a temporary form of privacy is an allure in those times of the year when certain cities urban spaces are more active under shelter.

Matthijs De Boer reinforces the logic of what makes an interior public, but this applies equally well to all three filament types - '(it) lies on an urban route, and is therefore easily accessible'. de Boer goes on to qualify its comfort levels, that is that it protects from the elements, and visitors need not worry about the maintenance of the space, or how actively engaged one need be with others in the space. [4, p. 19] This differs from the discussion Jacobs [7] elaborates at length on the purpose of active engagement with others on city streets.

When studying the changes in the space of shopping culture, de Boer comes to the conclusion that 'the role of the large urban public interiors is falling into 
the hands of commerce - shops and department stores, plaza and grand cafés.' In considering the challenges facing city planning de Boer does suggest that in addition to the form and siting considerations of proposals that 'it would not be a bad idea if the commission advising on the aesthetics of buildings also had a say in the design of the interior, or at least that part which is publicly accessible.' De Boer [4, p.26].

Adrian Forty makes reference to Lefebvre's The Production of Space, recalls in wonder Lefebvre's view how space is created- 'societies 'secrete' space, producing and appropriating it as they go along ", [5, p.38] and again using Lefebvre to express the need to 'architects and city-planners offered - as an ideology in action - an empty space, a space that is primordial, a container ready to receive fragmentary contents, an neutral medium into which disjointed things, people and habitats might be introduced' Forty [5, p. 308]. Urban filaments, having been rendered dormant in the drawings through much of the early and second wave of modernity, have emerged back into space that contains active content and new forms.

The Highline in New York's Chelsea area is the rehabilitation of the almostinvisible abandoned elevated rail space back into the public consciousness. It is an example of a ribbon urban filament. Embracing the elevated rail line as a defacto public space meant that even cities like NY could still operate nimbly at a large scale without massive disruption of existing figures and grounds. The telling formal quality of the space is that it stalled-out many future tower forms underneath it by championing its 'as found' qualities (notably the filtering views out to the city and the edge). As shown in figure 7, the qualities of the abandoned rail line have been largely preserved, with alterations and intensification of program altering the existing character along its length. The local firm Diller, Scofidio, and Renfro, has designed it with collaborations with landscape, local groups, benefactors and artists. Interestingly, the early conceptual proposal for this elevated space in the 1970's that would have it turned into housing by

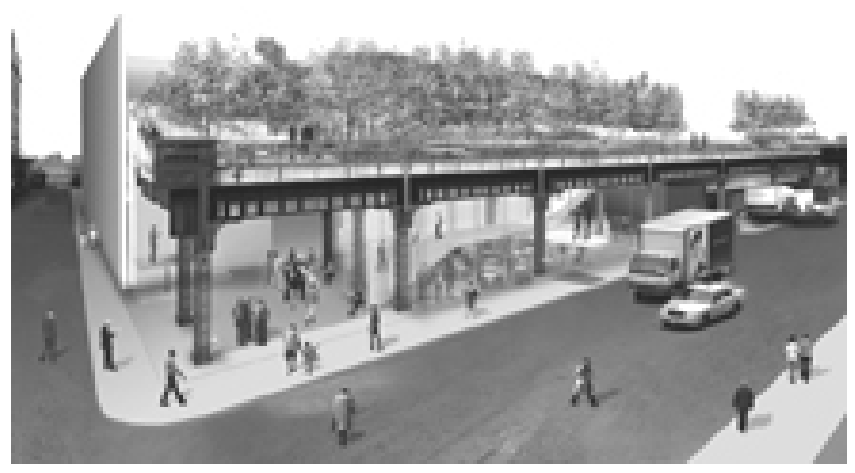

Figure 7: Computer rendering of the Highline urban park in New York City. 
Steven Holl isn't as prominent in the recent history of the site. Perhaps the transformation of this linear space from flow-space, as used by trains and now strollers and joggers didn't have the requisite collective use as public realm to use Holl's beautiful homes-on-a-bridge to fight the desires of those intent on building towers over the ghost of the rail in those formative months before this project could be realized.

When such a ribbon-urban filament is experienced, one may ask- why does it appear that so many of the modernist urban schemes were evading the issues of pedestrian circuits, context, comfort and amenity in medium to large urban centres? There is an overall sombre, windswept quality to the drawings of street life in many of these proposals, minimal, but without the draw that makes a simple street possess a life of its own. Richard Sennett, in The Fall of Public Man writes about such circulation spaces thus- 'Public space has become a derivative of movement.' [11, p. 14]

Another promising filament project - a public interior with interior event space elements completed in 1994-2003, by Herzog and de Meuron, the Swiss architectural firm, developed the Fünf Höfe - it was an infill/renovation of spaces defined by a collection of five business passageways in Munich. The overall planning of the spaces takes advantage of existing circulation, and introduces an alternative to the covered mall and linear open-air corridor. There are no fewer than 22 unique sky-courts integrated within 5 main paths/entrances working in concert to produce an intimate urban strolling/shopping experience they do this mainly with natural and artificial lighting and large concrete tiles that encourage cycling and movement though its open-air circulation, fig. 8 . These series of spaces dovetail with the existing pedestrian planning principles in use in the core of Munich, which echo the sense of discovery and trail system that weaves itself into the park and in new developments; strong planning policy here showcases how the art of shopping design can have soft borders and enhance existing collective dreams.

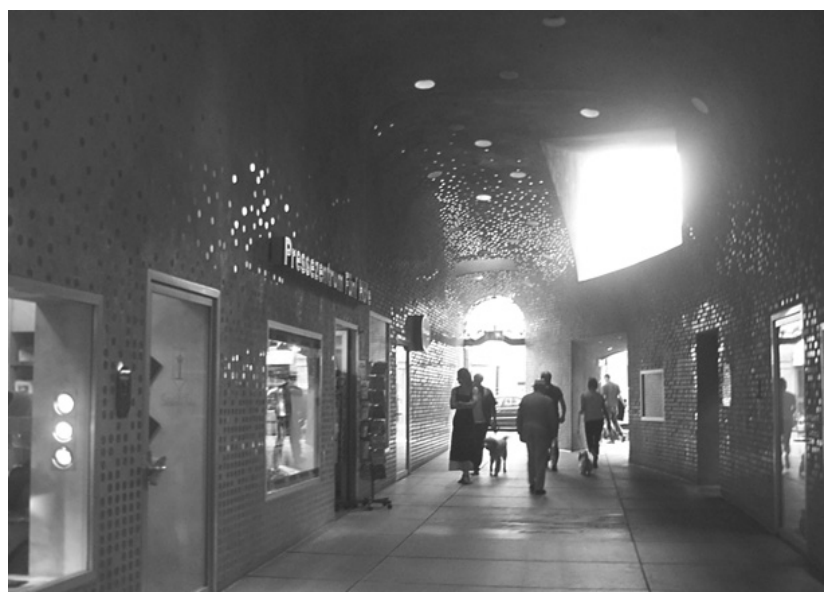

Figure 8: $\quad$ Fünf Höfe, Courtyard retail in Munich, Herzog and de Meuron. 


\section{Conclusion}

This paper explores the significance of the largely overlooked emergence in modernist architectural, interior design, and planning theory/practice, of the three proposed categories of urban filaments; interior event space, public interior, and ribbons - pedestrian circulation and how this street-that-is-not-a-street can offer solutions and emergent form for difficult urban conditions. Urban filaments contribute to sustainable city design in direct, personal ways - in our daily strolls and errands the city offers manifold opportunity to experience the unfolding patterning of human movement. These strategies can work in urbanizing new developments as well as in existing blocks and large-scale buildings, by recovering the benefits of thick social space in direct opposition to our attenuated street-life.

Perhaps it is best to conclude with George Baird's puzzlement about the oddness of how we circulate in our contemporary city as voiced in his text The Space of Appearance. We wonder at those big box warehouses where we all eventually shop, the vastness and hybrid condition of the West Edmonton Mall, the relentlessly long corridors in the airports we visit, concluding with that odd déjà-vu of replicating retail kiosks - have I been here before... all of 'these astonishing urban phenomena of the end of the twentieth century as yet await their Walter Benjamin...' Baird [2, p. 341].

\section{References}

[1] Alexander, Christopher, A Pattern Language, Oxford University Press: New York, pp. 488-498, 1977.

[2] Baird, George, The Space of Appearance, The MIT Press: Cambridge, 1995.

[3] Benjamin, Walter, The Arcades Project, (transl. by Eiland, Howard and McLaughlin, Kevin), The Belknak Press: Cambridge, 1999.

[4] De Boer, Matthijs, Kloos, Public Interiors (Chapter 2). Public Interiors: Architecture and Public Life Inside Amsterdam, ed., Kloos, Maarten, Architectura \& Natura Press: Amsterdam, pp. 9-31, 1999.

[5] Forty, Adrian, Words and Buildings: A Vocabulary of Modern Architecture, Thames \& Hudson Inc.: New York, pp. 86, 1896.

[6] Giedion, Sigfried, Space, Time and Architecture: The Growth of a New Tradition, Harvard University Press: Cambridge, Massachusetts, 1973.

[7] Jacobs, Jane, The Death and Life of Great American Cities (Chapter 9). The Need for Small Blocks, Vintage Books: New York, pp.178-186, 1992 (1961).

[8] Krier, Rob, Town Spaces, Birkhäuser: Boston, p. 2006. Phillipp Meuser, in his essay on town spaces 'Experiments with Convention pp: 248-265, in Krier, Town Spaces.

[9] Redfield, Wendy. The Suppressed Site: Revealing the Influence of Site on Two Purist Works. Site Matters, ed., Burns, Carol J., and Kahn, Andrea, Routledge: New York, pp. 184-222, 2005. 
274 The Sustainable City VI

[10] Rowe, Colin, As I Was Saying: Volume III, Urbanistics, The MIT Press: Cambridge, 1999.

[11] Sennett, Richard, The Fall of Public Man, Vintage Books: New York, pp. 3-27, 1978 (1974). 